\title{
KOSAKATA BERLADANG SUKU PASER DI KECAMATAN LONG IKIS: KAJIAN SEMANTIK
}

\section{FARMING VOCABULARIES OF PASER ETHNIC IN LONG IKIS DISTRICT: SEMANTICS STUDY}

\author{
Nurul Masfufah \\ Kantor Bahasa Kalimantan Timur \\ mashfufahnurul@yahoo.com
}

\begin{abstract}
ABSTRAK
Penelitian mengenai kosakata berladang masyarakat suku Paser ini penting dilakukan sebagai bentuk pelestarian dan pendokumentasian bahasa Paser. Tujuan penelitian ini adalah untuk mendeskripsikan bentuk dan makna kosakata berladang suku Paser di Kecamatan Long Ikis. Penelitian ini memanfaatkan kajian semantik leksikal untuk pengolahan data. Data dikumpulkan dari informan melalui teknik catat dan wawancara dengan alat perekam suara. Analisis data penelitian menggunakan teknik analisis deskriptif yang mencakup analisis data linguistik (semantik). Teknik analisis data dalam penelitian ini menggunakan analisis deskriptif, yaitu dengan analisis data linguistik (semantik). Adapun model analisis data yang digunakan, yaitu analisis model interaktif yang terdiri atas tiga komponen analisis, yaitu reduksi data, penyajian data, dan penarikan simpulan. Berdasarkan hasil penelitian dan pembahasan, diperoleh 35 kosakata berladang suku Paser yang terdiri atas lima klasifikasi, yaitu (a) proses pratanam berjumlah 9 kosakata, (b) alat membuka ladang berjumlah 4 kosakata, (c) proses menanam dan merawat padi berjumlah 4 kosakata, (d) proses memanen dan pascapanen berjumlah 9 kosakata, dan (e) alat untuk memanen dan pascapanen berjumlah 9 kosakata. Analisis konsep makna secara semantik juga dikaitkan dengan makna kultural masyarakat setempat karena dapat memperjelas makna kosakata berladang tersebut.
\end{abstract}

Kata kunci: kosakata, berladang, suku Paser, semantik

\begin{abstract}
The research on the farming vocabulary of the Paser ethnic is important as a form of preservation and inventory of the vocabulary. This study aims to describe the dictions and meaning of the farming vocabulary of the Paser ethnic in the Long Ikis District. This study uses lexical semantic studies to analyze the research data. The data were collected from informants through note-taking techniques and interviews with voice recorder tools. Analysis of research data using descriptive analysis techniques includes the analysis of linguistic (semantic) data. The data analysis technique in this study used the descriptive analysis, namely by analyzing linguistic (semantic) data. The data analysis model used is an interactive model analysis consisting of three components of analysis, namely data reduction, data presentation, and drawing conclusions. Based on the results of the research and discussion, there were 35 farming vocabularies of the Paser ethnic which consisted of five classifications, namely (a) pre-farming process totaling 9
\end{abstract}


vocabulary, (b) tools to open the fields consist of 4 vocabularies, (c) the process of planting and caring consists of 4 vocabularies, $(d)$ the process of harvesting and post-harvestingconsist of 9 vocabularies, and (e) tools for harvesting and post-harvestingconsist of 9 vocabularies. The analysis of the concept of semantic meaning is also associated with the cultural meaning of the local community because it can clarify the meaning of the farming vocabularies.

Keywords: vocabularies, farming, Paser ethnic, semantics

\section{PENDAHULUAN}

Masyarakat suku Paser di Kalimantan Timur, khususnya yang tinggal di daerah kampung atau kecamatan umumnya bermatapencaharian sebagai peladang tradisional. Cara berladang tradisional masyarakat Paser memiliki keunikan dan sudah dilakukan secara turun-temurun. Oleh karena itu, berladang merupakan kegiatan yang begitu dekat dengan masyarakat suku Paser, termasuk di Kecamatan Long Ikis. Mata pencaharian tradisional masyarakat Paser saat ini mulai terpinggirkan dan mulai hilang atau punah karena adanya mata pencaharian lainnya, yaitu bekerja di perkebunan kelapa sawit yang mulai marak di Kabupaten Paser.

Namun, kegiatan berladang suku Paser di Kecamatan Long Ikis hingga saat ini masih dilestarikan walaupun sudah tidak banyak lagi peladang dan lahan ladangnya. Kegiatan berladang suku Paser ini juga merupakan salah satu bentuk budaya, pengikat antara masyarakat dan leluhur mereka. Oleh karena itu, perlu dilakukan dokumentasi melalui kajian atau penelitian, salah satunya penelitian mengenai kosakata berladang masyarakat suku Paser. Penelitian mengenai kosakata berladang masyarakat suku Paser ini penting dilakukan sebagai usaha pendokumentasian bahasa Paser supaya tidak punah karena perubahan zaman. Oleh karena itu, ruang lingkup penelitian ini, yaitu mengenai kosakata berladang yang meliputi proses, alat, dan hasil berladang. Mulai dari kegiatan pramenanam, menanam, memanen, dan pascapanen untuk mata pencaharian berladang.

Septiandi, dkk.(2015) mengatakan bahwa dengan masih ada atau tidaknya kosakata dipakai dalam berinteraksi sosial di masyarakat, dapat membuktikan eksistensi kosakata dalam suatu bahasa.Oleh karena itu, diperlukan usaha untuk melestarikan kearifan daerah tersebut, salah satunya dengan pendokumentasian dan penelitian. Penelitian mengenai kosakata berladang juga belum pernah dilakukan di Kecamatan Long Ikis, Kabupaten Long Kali, baik oleh linguis maupun mahasiswa.

Penelitian ini dilakukan di Kecamatan Long Ikis, tepatnya di Desa Semuntai, Desa Tajur, dan Desa Brewe yang dihuni oleh komunitas suku Paser. Masyarakat suku Paser yang berada di Long Ikis tersebut tersebar di desa dan biasanya agak jauh dari pusat Kecamatan Long Ikis. Alasan peneliti memilih Desa Semuntai, Desa Tajur, dan Desa Brewe sebagai tempat penelitian, antara lain (1) kegiatan berladang di tiga desa tersebut masih dilakukan oleh masyarakat setempat. Kegiatan tersebut belum terlalu tergeser dengan perkebunan kelapa sawit yang saat ini mulai banyak dikembangkan di Kecamatan Long Ikis. (2) Proses berladang masyarakat suku Paserpada umumnya masih bersifat tradisional. Mereka masih menggunakan dataran tinggi atau perbukitan sebagai lahan 
perladangan dan masih menggunakan alat tradisional, tanpa menggunakan mesin. (3) Masih kurangnya mobilitas masyarakat pendatang ke desa tersebut sehingga secara tidak langsung mengurangi kontaminasi bahasa dan budaya suku Paser. (4) Dari segi geografis, Desa Semuntai, Desa Tajur, dan Desa Brewe masih banyak terdapat area bukit yang luas sehingga tempat untuk berladang mereka tidak menjadi masalah. (5) Dari aspek budaya, adat, atau ritual, proses berladang masih dilakukan secara turun-temurun dan dilestarikan, khususnya di Desa Brewe. Masyarakat di tiga desa tersebut tidak hanya menanam padi untuk mendapatkan beras, tetapi juga menjadikan kegiatan berladang itu sebagai wadah bagi mereka untuk menjunjung semangat gotong-royong, kegigihan, dan kesabaran dalam mencari pangan. Penelitian ini diharapkan dapat mendokumentasikan dengan baik kosakata berladang suku Paser sebagai usaha pelestarian kearifan lokal, masyarakat di Kabupaten Paser, khususnya di Kecamatan Long Ikis.

Kajian awal tentang bahasa Paser telah dilakukan oleh Darmansyah, dkk. pada tahun 1979 dari segi fonologi, morfologi, dan sintaksis. Pada tahun 2014, Rusbiyantoro, dkk. Melakukan penyusunan terhadap kosakata bahasa Paser dan sudah diterbitkan dalam bentuk Kamus Bahasa Paser-Bahasa Indonesia yang memiliki jumlah sekitar 3200 lema. Hal tersebut dilakukan sebagai upaya pelestarian nilai-nilai budaya daerah yang sangat penting artinya bagi pembangunan negara dan bangsa. Selain itu, hal itu juga merupakan upaya untuk mendokumentasikan kosakata bahasa Paser sehingga keberadaannya dapat dipertahankan (Rusbiyantoro, 2014). Namun, kajian dari aspek sosiolinguistik dan semantik jarang dilakukan. Oleh karena itu, perlu dilakukan kajian dari aspek tersebut.

Penelitian terdahulu yang sesuai dengan penelitian ini, antara lain penelitian Septiandi, dkk. (2015) dengan judul "Kosakata Berladang Padi Suku Dayak Kubitn Kecamatan Pinoh selatan: Kajian Semantik Leksikal". Penelitian ini memofuskan pada kajian makna dan komponennya dengan menggunakan kajian semantik leksikal. Simon (2017), mahasiswa Universitas Tanjungpura menyusun penelitian berjudul "Peristilahan dalam Beumo (Berladang Padi) pada Masyarakat Dayak Ketungau Sesat: Kajian Semantik". Penelitian ini mengkajiklasifikasi dan komponen makna peristilahan berladang padi dalam masyarakat Dayak Ketungau Sesat. Selanjutnya, penelitian yang dilakukan oleh Budhiono (2017), Balai Bahasa Kalimantan Tengah yang berjudul "Leksikon Alat dan Aktivitas Bertanam Padi dalam Bahasa Jawa". Penelitian tersebut menitikberatkan pada deskripsi masingmasing leksem tanpa diklasifikasikan.

Penelitian ini memiliki persamaan dengan penelitian tersebut, yaitu meneliti kegiatan berladang, khususnya padi dengan menggunakan tinjauan semantik. Adapun perbedaan penelitian ini, yaitu daerah pengamatan dan bahasa yang diteliti. Perbedaan daerah pengamatan dan bahasa ini dapat mempengaruhi aspek budaya dan keunikan suku atau etnik tersebut sehingga dapat mempengaruhi perbedaan dalam hal proses, alat, dan sebagainya saat berladang padi. Selain itu, penelitian ini lebih mengkaji pada bentuk dan konsep makna pada kosakata yang sudah diklasifikasi sehingga mempermudah pembaca untuk memahami.

Fokus masalah yang akan dikaji dalam penelitian ini, yaitu bagaimana bentuk dan makna kosakata berladang suku Paser di Kecamatan Long Ikis 
berdasarkan kajian semantik. Adapun tujuan penelitian ini, yaitu mendeskripsikan bentuk dan makna kosakata berladang suku Paser di Kecamatan Long Ikis berdasarkan kajian semantik. Manfaat dari penelitian ini, antara lain (1) sebagai sumber dokumentasi, (2) sebagai sumber pengayaan kosakata bahasa Indonesia dan daerah karena banyak terdapat kosakata yang memiliki konsep berbeda dan memiliki keunikan tersendiri, (3) sebagai sumber informasi budaya karena kajian ini juga berkaitan dengan budaya suku Paser, khususnya tentang sistem berladangnya.

Penelitian kosakata berladang suku Paser di Kecamatan Long Ikis ini menggunakan kajian semantik leksikal. Semantik leksikal merupakan bagian dari ilmu yang mengkaji makna kosakata. Hal tersebut sangat relevan dengan objek penelitian ini, yaitu kosakata berladang pada masyarakat suku Paser di Kecamatan Long Ikis, Kabupaten Paser. Penelitian yang mengkaji dari aspek semantik dalam bahasa Paser ini belum banyak dilakukan, apalagi mengenai kajian kosakata berladang suku Paser.

Bahasa Paser merupakan bahasa ibu dan bahasa komunikasi bagi orang Paser. Bahasa Paser dituturkan oleh masyarakat di Kelurahan Sepaku dan Kelurahan Mentawir, Kecamatan Sepaku; di Kelurahan Sotek, Kecamatan Penajam; di Desa Babulu Darat, Kecamatan Babulu; di Kelurahan Long Kali, Kecamatan Long Kali; dan di Desa Samuntai, Kecamatan Long Ikis, Kabupaten Penajam Paser Utara. Selain di Kabupaten Penajam Paser Utara, bahasa Paser juga dituturkan di Kabupaten Paser. Di Kabupaten Paser, bahasa Paser dituturkan di Desa Sandeley, Kecamatan Kuaro; di Desa Swan Slutung dan Desa Muara Langon, Kecamatan Muara Komam; di Desa Busui, Kecamatan Batu Sopang; di Desa Lomu dan Desa Kerang, Kecamatan Batu Engau; di Desa Pasir Belengkong dan Desa Bekoso, Kecamatan Pasir Belengkong; di Kelurahan Long Kali, di Desa Muara Toyu, dan di Desa Kepala Telake, Kecamatan Long Kali (Tim Pemetaan Bahasa: 2017: 96-97). Menurut penghitungan dialektometri, isolek Paser tersebut merupakan sebuah bahasa yang memiliki persentase perbedaan sekitar 81\% - 100\% apabila dibandingkan dengan bahasa-bahasa lainnya yang ada di Provinsi Kalimantan Timur, misalnya dengan bahasa Basap, bahasa Benuaq, bahasa Bulungan, bahasa Punan Merah, bahasa Dusun, dan bahasa Long Lamcin (Tim Pemetaan Bahasa: 2017: 97).

Menurut Kridalaksana (2008:216), semantik merupakan bagian struktur bahasa yang bertalian dengan makna ungkapan dan juga dengan struktur makna suatu wacana. Semantik biasanya berhubungan dengan dua aspek lain, yaitu sintaksis sebagai pembentukan simbol kompleks dari simbol yang lebih sederhana, serta pragmatik sebagai penggunaan praktis simbol oleh komunitas pada konteks tertentu. Palmer dalam Suwandi (2008:9) menyatakan bahwa semantics is the technical term used to refer to the study of meaning, and since meaning is a part of language, semantics is a part of linguistics. Dengan demikian, semantik merupakan istilah teknis yang digunakan untuk mengkaji makna dan karena makna tersebut merupakan bagian dari bahasa, semantik tersebut merupakan bagian dari linguistik. Hal tersebut senada dengan pendapat Chaer (2013:2) yang menjelaskan bahwa semantik merupakan salah satu bidang ilmu linguistik yang mempelajari hubungan antara tanda-tanda linguistik dan hal- 
hal yang ditandainya. Dengan kata lain, semantik adalah bidang kajian dalam linguistik yang mempelajari makna. Dengan kata lain, semantik mengandung pengertian kajian mengenai makna. Seperti halnya bunyi dan tata bahasa, komponen makna dalam hal ini juga menduduki tingkat tertentu. Artinya, apabila komponen bunyi menduduki tingkat pertama, tata bahasa pada tingkat kedua, makna menduduki tingkat ketiga. Ketiga komponen tersebut bertalian karena bahasa pada awalnya merupakan bunyi abstrak, mengacu pada lambang-lambang yang memiliki tatanan bahasa yang berbentuk dan diasosiasikan dengan makna (Aminuddin, 2003:15).

Makna dari satuan-satuan bahasa, seperti kata, frasa, klausa, kalimat, dan wacana merupakan objek kajian semantik. Ada beberapa jenis kajian semantik yang dibedakan berdasarkan tataran atau bagian dari bahasa yang diteliti, salah satunya semantik leksikal. Semantik leksikal yang dimaksud adalah semantik yang mengkaji leksikon dari suatu bahasa. Semantik leksikal tersebut menyelidiki atau mengkaji makna yang ada pada leksem-leksem bahasa (Chaer, 2013:8). Oleh karena itu, makna yang ada pada leksem-leksem itu disebut makna leksikal. Lebih lanjut, Chaer (2013:8) menjelaskan bahwa leksem merupakan istilah yang sering digunakan dalam kajian semantik untuk menyebut satuan bahasa yang memiliki makna. Istilah leksem tersebut kurang lebih dapat disamakan dengan istilah kata sebagai satuan gramatikal bebas terkecil yang sering digunakan dalam kajian morfologi dan sintaksis.

Adiwimarta dalam Muhidin (2015:81) menyatakan bahwa kosakata merupakan semua kata yang terdapat dalam suatu bahasa. Kosakata dapat berupa kata-kata atau istilah yang digunakan dalam satu bidang ilmu pengetahuan tertentu (Muhidin, 2015:81). Secara jelas, Kridalaksana (2008:142) memaparkan mengenai kosakata, yaitu (1) komponen bahasa yang mengandung informasi tentang makna dan pemakaian kata dalam suatu bahasa; (2) kekayaan atau perbendaharaan kata yang dimiliki oleh pembicara, penulis, atau suatu bahasa; dan (3) daftar kata yang disusun seperti kamus, tetapi dengan penjelasan yang lebih singkat dan praktis.Kosakata yang dimaksud dalam penelitian ini, yaitu katakata yang terdapat dalam rangkaian kegiatan berladang. Mengacu pada pendapat Chaer (2013:8), makna leksikal merupakan makna bahasa yang sesuai dengan referen atau hal yang ditunjuknya. Makna yang sesuai dengan hasil observasi alat indra atau makna yang sungguh-sungguh nyata dalam kehidupan. Makna leksikal dalam penelitian ini, yaitu makna yang didapatkan dan disesuaikan dengan maksud penutur atau informan dari suku Paser di Desa Semuntai, Tajur, dan Brewe yang memaknai kegiatan berladang tersebut.

\section{METODE}

Metode yang digunakan dalam penelitian adalah metode deskriptif, yakni penelitian yang berusaha mendeskripsikan suatu gejala, peristiwa, kejadian yang terjadi saat sekarang. Teknik yang dilakukan peneliti dalam pengumpulan data, yaitu dengan teknik wawancara. Widoyoko (2013:40) menjelaskan bahwa wawancara merupakan suatu proses tanya jawab atau dialog secara lisan antara pewawancara dengan responden atau orang yang diinterviu dengan tujuan untuk memperoleh informasi yang dibutuhkan oleh peneliti. Wawancara dalam 
penelitian kualitatif dilakukan secara tidak terstruktur atau sering disebut sebagai teknik wawancara mendalam karena peneliti merasa belum mengetahui hal yang diinginkan. Saat menyimak dan berwawancara dengan informan, peneliti menggunakan teknik catat untuk mencatat hal-hal penting berkaitan dengan data atau mencatat bagian-bagian yang sekiranya akan ditanyakan kembali kepada informan.

Informan dalam penelitian ini terdiri atas informan utama, yaitu Bapak Amen (65 tahun) dan informan pendamping, yaitu Bapak Bardun (67 tahun) dan Bapak Kuran (59 tahun). Informan tersebut dipilih dengan menggunakan kriteria tertentu. Dalam memilih informan, peneliti menggunakan kriteria yang dikemukakan oleh Nothofer (1991:5) dalam Rahman, dkk. (2014:13), yaitu sebagai berikut:

(1) berjenis kelamin laki-laki atau perempuan,

(2) berusia 30 s.d. 60 tahun,

(3) lahir dan besar di daerah setempat,

(4) mobilitasnya kurang,

(5) dapat berbahasa daerah setempat,

(6) dapat berbahasa Indonesia, dan

(7) sehat rohani dan jasmani dalam arti alat bicaranya sempurna.

Waktu penelitiannya dilakukan selama 5 bulan, yaitu dari bulan Februari sampai dengan Juni. Dimulai dari tahap persiapan, pengumpulan data, pengolahan atau analisis data (meliputi klasifikasi data, transkripsi fonetis berdasarkan pelafalannya, pemenggalan, penentuan kelas kata, dan pemaknaan), penyajian hasil dan pembahasan, sampai dengan penyimpulan.

Teknik analisis data dalam penelitian ini menggunakan analisis deskriptif, yaitu dengan analisis data linguistik (semantik). Adapun model analisis data yang digunakan dalam penelitian ini adalah analisis model interaktif, seperti yang dikemukakan Miles dan Huberman (2007:19-20) yang terdiri atas tiga komponen analisis, yaitu: reduksi data, penyajian data, dan penarikan simpulan. Adapun langkah yang dilakukan, yaitu mentranskripsikan hasil rekaman dan catatan, lalu membaca hasil transkripsi tersebut, mengklasifikasi data, kemudian mengolah dan menganalisis data berdasarkan masalah yang akan dikaji, dan dilanjutkan dengan membahas dan menyimpulkan hasil analisis data.

\section{HASIL DAN PEMBAHASAN}

Hasil penelitian ini berupa data kosakata berladang suku Paser di Kecamatan Long Ikis. Dari data penelitian yang sudah dikumpulkan (35 kosakata), kemudian dilakukan pengolahan data yang meliputi klasifikasi dan deskripsi data. Dari pengolahan data tersebut, diperoleh klasifikasi data, yaitu berdasarkan proses pratanam, alat membuka ladang, proses menanam dan merawat, proses memanen dan pascapanen, alat memanen dan pascapanen. Berikut ini tabel kosakata berladang suku Paser dan deskripsi makna berdasarkan klasifikasi tersebut. 
Tabel 1

Kosakata Mengenai Proses Pratanam Padi

\begin{tabular}{|c|c|c|c|c|c|}
\hline No. & $\begin{array}{c}\text { Kosakata } \\
\text { Proses } \\
\text { Pratanam } \\
\end{array}$ & Pelafalan & $\begin{array}{c}\text { Pemenggal- } \\
\text { an }\end{array}$ & Makna & $\begin{array}{l}\text { Kelas } \\
\text { Kata }\end{array}$ \\
\hline 1. & metoilek & $\mathrm{m}$ |toilEk & me.to.i.lek & $\begin{array}{l}\text { memeriksa atau } \\
\text { menyurvei }\end{array}$ & verba \\
\hline 2. & mombas & mombas & mom.bas & $\begin{array}{l}\text { menebas pohon } \\
\text { atau kayu kecil }\end{array}$ & verba \\
\hline 3. & notow & notow & no.tow & $\begin{array}{l}\text { menebang pohon } \\
\text { atau kayu besar }\end{array}$ & verba \\
\hline 4. & jowak & jowa? & jo.wak & $\begin{array}{l}\text { mengumpulkan } \\
\text { kayu yang sudah } \\
\text { ditebangi }\end{array}$ & verba \\
\hline 5. & jotok & jOtO? & jo.tok & $\begin{array}{lr}\text { merapikan } & \text { kayu } \\
\text { yang } & \text { sudah } \\
\text { dikumpulkan }\end{array}$ & verba \\
\hline 6. & neket & nEkEt & ne.ket & $\begin{array}{lr}\text { membakar } & \text { kayu } \\
\text { yang } & \text { sudah } \\
\text { dirapikan/ditata }\end{array}$ & verba \\
\hline 7. & ngonduk & GOndu? & ngon.duk & $\begin{array}{l}\text { mengumpulkan } \\
\text { kembali sisa-sisa } \\
\text { kayu yang sudah } \\
\text { dibakar }\end{array}$ & verba \\
\hline 8. & торо & mopo & mo.po & $\begin{array}{l}\text { membersihkan } \\
\text { kayu-kayu kecil } \\
\text { dan rumput di } \\
\text { sekitar } \\
\text { pembakaran }\end{array}$ & verba \\
\hline 9. & mombak & momba? & mom.bak & $\begin{array}{l}\text { membersihkan } \\
\text { lahan atau ladang } \\
\text { untuk dipakai } \\
\text { kedua kalinya }\end{array}$ & verba \\
\hline
\end{tabular}

Berdasarkan tabel di atas, pada proses pratanam padi suku Paser di Kecamatan Long Ikis, ditemukan sembilan bentuk kosakata. Kesembilan kosakata tersebut berkelas kata verba karena berupa kegiatan atau melakukan sesuatu. Berikut ini akan dijelaskan secara singkat konsep makna pada kesembilan kosakata tersebut. Kata metoilek memiliki makna memeriksa atau menyurvei lahan atau hutan yang akan dijadikan ladang. Kegiatan metoilek ini dilakukan perorangan. Biasanya dilakukan oleh kaum laki-laki yang memiliki lahan atau ladang tersebut. Kata mombas bermakna menebas kayu-kayu kecil atau pohonpohon kecil dengan menggunakan otak atau parang dan pakakait atau sejenis tongkat pengait yang terbuat dari kayu untuk menyangkutkan dan menahan pohon 
kecil atau dahan-dahan tersebut agar tidak mengenai orang yang menebas tersebut. Kata notow bermakna menebang kayu-kayu besar atau pohon besar dan agak besar dengan menggunakan wase atau sejenis kampak atau beliung.

Sementara itu, kata jowak memiliki makna mengumpulkan kayu yang sudah ditebas atau ditebang sebelum dibakar. Kata jotok memiliki makna merapikan kayu-kayu yang sudah dikumpulkan. Biasanya setelah dikumpulkan dan dirapikan, kayu dibiarkan dulu sampai kering agar mudah untuk dibakar. Kata neket mengacu pada makna membakar kayu-kayu yang sudah dikumpulkan dan dirapikan. Kata ngonduk memiliki makna mengumpulkan kembali sisa-sisa kayu yang sudah dibakar. Kata mopo bermakna membersihkan lagi rumput-rumput kecil dan kayu-kayu kecil. Kata mombak mengacu pada makna membersihkan lahan atau ladang untuk dipakai kedua kalinya.

Kosakata bahasa Paser yang berkaitan dengan alat yang digunakan untuk membuka ladang, antara lain, sebagai berikut.

\section{Tabel 2}

\section{Kosakata Mengenai Alat untuk Membuka Ladang}

\begin{tabular}{|l|l|l|l|l|c|}
\hline No. & $\begin{array}{c}\text { Kosakata Alat } \\
\text { Berladang }\end{array}$ & Pelafalan & $\begin{array}{c}\text { Pemenggal- } \\
\text { an }\end{array}$ & \multicolumn{1}{|c|}{ Makna } & $\begin{array}{c}\text { Kelas } \\
\text { Kata }\end{array}$ \\
\hline 1. & otak & ota? & o.tak & $\begin{array}{l}\text { sejenis arang } \\
\text { atau golok }\end{array}$ & nomina \\
\hline 2. & pakakait & pakakait & pa.ka.ka.it & tongkat pengait & nomina \\
\hline 3. & wase & wase & wa.se & sejenis kapak & nomina \\
\hline 4. & cangkul & caGkul & cang.kul & cangkul & nomina \\
\hline
\end{tabular}

Pada tabel di atas, dapat dilihat bahwa alat untuk membuka ladang pada masyarakat suku Paser hanya ditemukan empat bentuk kosakata. Keempat kosakata tersebut merupakan kelas kata nomina karena berupa bentuk alat. Berikut ini akan dijelaskan secara singkat konsep makna dari keempat kosakata alat untuk membuka ladang tersebut. Kata otak mengacu pada makna pisau besar (lebih besar daripada pisau, tetapi lebih pendek daripada pedang, ada bermacammacam bentuknya, terbuat dari logam besi dan pegangannya dari kayu. Penyebutannya tetap sama walaupun bentuknya bermacam-macam. Alat ini untuk menebas pohon-pohon kecil dan rumput-rumput pada saat membuka ladang atau lahan.

Sementara itu, kata pakakait memiliki makna sejenis tongkat pengait yang terbuat dari kayu untuk membantu pada saat menebas pohon-pohon kecil atau dahan-dahan. Jadi, pakakait tersebut digunakan untuk menyangkutkan dan menahan pohon kecil atau dahan-dahan yang akan ditebas sehingga tidak terkena orang yang menebas tersebut. Kata wase bermakna sejenis kapak yang terbuat dari logam dan bertangkai panjang menggunakan tali atau kayu untuk menebang atau memotong pohon-pohon yang besar. Kata cangkul mengacu pada konsep makna alat untuk menggali tanah, dalam hal ini, untuk membuat alur pada tanah sebagai batas antara lahan hutan di sekitarnya supaya tidak merembet terbakar. Cangkul ini terbuat dari lempeng besi dan diberi tangkai panjang untuk pegangan. 
Kosakata bahasa Paser yang berkaitan dengan proses menanam dan merawat padi dapat dilihat pada tabel di bawah ini.

Tabel 3

Kosakata Mengenai Proses Menanam dan Merawat Padi

\begin{tabular}{|l|l|l|l|l|l|}
\hline No. & $\begin{array}{c}\text { Kosakata } \\
\text { Proses } \\
\text { Menanam } \\
\text { dan Merawat }\end{array}$ & Pelafalan & $\begin{array}{c}\text { Pemenggal- } \\
\text { an }\end{array}$ & \multicolumn{1}{|c|}{ Makna } & $\begin{array}{c}\text { Kelas } \\
\text { Kata }\end{array}$ \\
\hline 1. & $\begin{array}{l}\text { nasokatau } \\
\text { nugal }\end{array}$ & nugal & $\begin{array}{l}\text { na.sokatau } \\
\text { nu.gal }\end{array}$ & $\begin{array}{l}\text { menanam biji padi } \\
\text { dengan tugal }\end{array}$ & verba \\
\hline 2. & mopo & mopo & mo.po & $\begin{array}{l}\text { membersihkan } \\
\text { rumput dengan } \\
\text { parang verba }\end{array}$ & verba \\
\hline 3. & ngerikut & G|rikut & nge.ri.kut & $\begin{array}{l}\text { membersihkan } \\
\text { rumput dengan } \\
\text { tangan atau parang } \\
\text { kecil }\end{array}$ & \\
\hline 4. & namuk & namu? & na.muk & mengasapi & verba \\
\hline
\end{tabular}

Berdasarkan tabel di atas, pada proses menanam dan merawat padi suku Paser di Kecamatan Long Ikis, ditemukan empat bentuk kosakata. Keempat kosakata tersebut berkelas kata verba karena berupa kegiatan atau melakukan sesuatu. Pertama, kata nasok atau nugal, mengacu pada konsep makna menanam biji padi di ladang dengan cara melubangi tanah menggunakan kayu atau tugal. Cara menugal masyarakat suku Paser, yaitu dengan cara berombongan sekitar 30 - 40 orang yang dipimpin satu orang biasanya pemilik lahan padinya. Apabila lahannya tidak terlalu luas ( $1-2 \mathrm{ha})$, kegiatan itu dapat dikerjakan sehari penuh. Biasanya banyak dikerjakan oleh kaum perempuan yang tugasnya menaruh benih padi di lubang tanah. Kaum laki-laki biasanya membuat lubang atau menugal.

Kedua, kata mopo memiliki makna membersihkan rumput di ladang dengan otak atau parang yang dilakukan oleh kaum laki-laki. Ketiga, kata ngerikut bermakna membersihkan rumput di sela-sela padi yang umurnya sekitar 3-4 minggu. Kegiatan ini biasanya dilakukan oleh kaum perempuan. Keempat, kata namuk mengacu pada makna mengasapi atau membuat asap dari kulit kayu tendangi yang baunya wangi pada saat bersih-bersih. Asapnya dapat mengusir nyamuk dan juga dapat memberikan nutrisi yang baik untuk tanaman padi.

Kosakata bahasa Paser yang berkaitan dengan proses panen dan pascapanen, khususnya untuk tanaman padi, antara lain, sebagai berikut. 
Tabel 4

Kosakata Mengenai Proses Panen dan Pascapanen

\begin{tabular}{|c|c|c|c|c|c|}
\hline No. & $\begin{array}{c}\text { Kosakata } \\
\text { Proses } \\
\text { Panen dan } \\
\text { Pascapanen } \\
\end{array}$ & Pelafalan & $\begin{array}{c}\text { Pemenggal- } \\
\text { an }\end{array}$ & Makna & $\begin{array}{l}\text { Kelas } \\
\text { Kata }\end{array}$ \\
\hline 1. & ngani & Gani & nga.ni & $\begin{array}{l}\text { memetik padi dengan } \\
\text { ani-ani }\end{array}$ & verba \\
\hline 2. & $\begin{array}{l}\text { moson } \\
\text { karung }\end{array}$ & $\begin{array}{l}\text { mOsOn } \\
\text { karuG }\end{array}$ & $\begin{array}{l}\text { mo.son } \\
\text { ka.rung }\end{array}$ & $\begin{array}{l}\text { memindahkan padi } \\
\text { dari lahan ke pondok } \\
\text { lading dengan karung } \\
\text { besar }\end{array}$ & verba \\
\hline 3. & $m a b a$ & maba & $m a . b a$ & $\begin{array}{l}\text { membawa padi yang } \\
\text { sudah dikarungi dari } \\
\text { ladang ke rumah }\end{array}$ & verba \\
\hline 4. & nuyas & nuyas & nu.yas & $\begin{array}{l}\text { merontokkan padi } \\
\text { dari tangkainya } \\
\text { dengan kaki }\end{array}$ & verba \\
\hline 5. & jenjam & j|njam & jen.jam & $\begin{array}{l}\text { membersihkan gabah } \\
\text { dari kotoran dengan } \\
\text { tangan }\end{array}$ & verba \\
\hline 6. & niyau & niyauw & ni.yau & $\begin{array}{l}\text { membersikan gabah } \\
\text { dengan alat tampi }\end{array}$ & verba \\
\hline 7. & keneke pare & $\begin{array}{l}\text { k|neke } \\
\text { pare }\end{array}$ & $\begin{array}{l}\text { ke.ne.ke } \\
\text { pa.re }\end{array}$ & $\begin{array}{l}\text { menjemur padi atau } \\
\text { gabah dengan alas } \\
\text { tikar }\end{array}$ & verba \\
\hline 8. & nonak & nona? & no.nak & $\begin{array}{l}\text { menyimpan padi atau } \\
\text { gabah }\end{array}$ & verba \\
\hline 9. & mutu & mutu & mu.tu & $\begin{array}{l}\text { menumbuk gabah } \\
\text { yang sudah kering } \\
\text { untuk menghasilkan } \\
\text { beras }\end{array}$ & verba \\
\hline
\end{tabular}

Pada tabel di atas, dapat dilihat bahwa pada proses menanam dan merawat padi suku Paser di Kecamatan Long Ikis, ditemukan sembilan bentuk kosakata. Kesembilan kosakata tersebut merupakan kelas kata verba karena berupa kegiatan atau melakukan sesuatu. Berikut ini akan dijelaskan secara singkat konsep makna dari sembilan kosakata proses kegiatan memetik padi dengan menggunakan alat renggap atau ani-ani yang terbuat dari kayu dan bambu yang saling menyilang dengan pisau kecil yang ditancapkan pada bagian muka kayu. Alat ini biasanya biasanya digunakan oleh kaum perempuan. Sementara itu, kaum laki-laki juga ikut membantu memetik padi yang dipanen, yaitu dengan alat selombang. Kata selombang mengacu pada makna alat pemotong padi yang terbuat dari kaleng bekas yang dibelah atau dipotong, panjangnya menyesuaikan jari jempol. Setelah 
dipotong atau dibelah, potongan kaleng tersebut dibentuk dengan cara digulung disesuaikan bentuk jari jempolnya. Alat ini biasanya digunakan oleh kaum lakilaki.

Pada saat memetik padi atau memanen, mereka menggunakan solong yang digendong di belakang punggungnya untuk menaruh padi yang sudah dipetik. Kata moson karung memiliki makna memindahkan padi yang sudah dipanen dari lahan ke pondok ladang dan dimasukkan ke dalam karung besar sebelum dibawa atau diangkut ke rumah. Kata maba mengacu pada makna kegiatan membawa padi yang sudah dikarungi dari ladang ke rumah dengan dipanggul. Kata nuyas bermakna kegiatan merontokkan atau melepaskan padi dari tangkainya dengan menggunakan kaki dengan jalan diinjak-injak. Kegiatan ini dapat dilakukan di ladang dan di rumah.

Sementara itu, kata jenjam mengacu pada konsep makna kegiatan membersihkan gabah dari batang atau tangkai-tangkai kecil dan gabah yang kosong dengan menggunakan tangan dengan cara diangkat-angkat sehingga sampah-sampahnya terbang, termasuk gabah yang kosong tersebut. Kata niyauw memiliki makna kegiatan membersihkan padi atau gabah dengan menggunakan alat tampi atau lewong sebelum proses penjemuran. Selain itu, untuk membersihkan padi atau gabah dari kotorannya, masyarakat Paser biasanya menggunakan alat usar atau sejenis tampi yang bentuknya bulat dengan anyaman rapat di pinggir, tetapi di tengahnya berongga. Frasa ngeke pare mengacu pada makna kegiatan menjemur padi atau gabah dengan alas apay atau sejenis tikar. Biasanya proses penjemurannya sampai gabah menjadi kering membutuhkan waktu selama tiga hari apabila matahari terik.

Kata nonak, bermakna menyimpan padi atau gabah, baik yang sudah dijemur maupun yang belum dijemur. Kata mutu memiliki konsep makna kegiatan menumbuk padi atau gabah yang sudah kering untuk menghasilkan beras. Kegiatan mutu yang masih tradisional ini menggunakan alat tradisional, yaitu lisung atau lesung dengan cara ditumbuk menggunakan kayu berat sebagai alu atau alat penumbuknya. Kegiatan ini dilakukan oleh ibu-ibu dan bapak-bapak dengan beramai-ramai sambil bernyanyi atau bercanda supaya tidak terasa lelah. Namun, kegiatan mutu ini sekarang jarang dilakukan karena saat ini sudah ada alat penggiling padi yang kerjanya lebih cepat karena menggunakan mesin. Masyarakat Paser saat ini kecenderungannya menggilingkan padinya kepada jasa penggiling padi.

Kosakata bahasa Paser yang berkaitan dengan alat yang digunakan untuk memanen padi dapat dilihat pada tabel di bawah ini.

Tabel 5

Kosakata Mengenai Alat untuk Memanen dan Pascapanen

\begin{tabular}{|l|l|l|l|l|l|}
\hline No & $\begin{array}{c}\text { Kosakata Alat } \\
\text { Panen dan } \\
\text { Pascapanen }\end{array}$ & Pelafalan & $\begin{array}{c}\text { Pemenggal- } \\
\text { an }\end{array}$ & \multicolumn{1}{|c|}{ Makna } & $\begin{array}{c}\text { Kelas } \\
\text { Kata }\end{array}$ \\
\hline 1. & renggap & r|Ggap & reng.gap & $\begin{array}{l}\text { alat pemotong padi } \\
\text { (ani-ani) }\end{array}$ & nomina \\
\hline
\end{tabular}


Tahun XIII Volume 13 Nomor 2 Edisi 6 Desember 2019

ISSN 0216-079X E-ISSN 2685-3043

Balai Bahasa Kalimantan Barat

\begin{tabular}{|c|c|c|c|c|c|}
\hline 2. & selombang & s|lombaG & se.lom.bang & $\begin{array}{l}\text { alat pemotong padi } \\
\text { yang dipasang } \\
\text { dijari jempol }\end{array}$ & nomina \\
\hline 3. & solong & soloG & so.long & $\begin{array}{lr}\text { sejenis tas } & \text { besar } \\
\text { dari rotan } & \text { yang } \\
\text { digunakan } & \text { di } \\
\text { punggung } & \end{array}$ & nomina \\
\hline 4. & kirai & kirai & ki.rai & $\begin{array}{l}\text { sejenis keranjang } \\
\text { besar }\end{array}$ & nomina \\
\hline 5. & selipir & s|lipir & se.li.pir & $\begin{array}{l}\text { tempat } \\
\text { penumpukan padi } \\
\text { seperti lumbung } \\
\text { padi yang terbuat } \\
\text { dari kulit kayu }\end{array}$ & nomina \\
\hline 6. & $\begin{array}{l}\text { tekalak bua } \\
\text { pare }\end{array}$ & $\begin{array}{l}\text { t|kala? } \\
\text { bua pare }\end{array}$ & $\begin{array}{l}\text { te.ka.lak } \\
\text { bu.a pa.re }\end{array}$ & $\begin{array}{l}\text { anyaman bambu } \\
\text { seperti bubu yang } \\
\text { diletakkan di } \\
\text { tengah-tengah } \\
\text { selipir }\end{array}$ & nomina \\
\hline 7. & $\begin{array}{l}\text { jakung atau } \\
\text { jayung }\end{array}$ & $\begin{array}{l}\text { jakuG } \\
\text { jayuG }\end{array}$ & $\begin{array}{l}\text { ja.kung atau } \\
\text { ja.yung }\end{array}$ & $\begin{array}{l}\text { Alas untuk } \\
\text { merontokkan padi } \\
\text { dari tangkainya, } \\
\text { terbuat dari bambu } \\
\text { yang dianyam dan } \\
\text { berongga agar padi } \\
\text { bias keluar }\end{array}$ & nomina \\
\hline 8. & $\begin{array}{l}\text { lewong atau } \\
\text { usar }\end{array}$ & $\begin{array}{l}\text { lewoG, } \\
\text { usar }\end{array}$ & $\begin{array}{l}\text { le.wong atau } \\
\text { u.sar }\end{array}$ & $\begin{array}{l}\text { sejenis tampi } \\
\text { untuk } \\
\text { membersihkan } \\
\text { padi dari kotoran }\end{array}$ & nomina \\
\hline 9. & pendakak & p|ndaka? & pen.da.kak & $\begin{array}{l}\text { sejenis tikar yang } \\
\text { terbuat dari daun } \\
\text { nipah atau dari } \\
\text { rotan untuk } \\
\text { menjemur padi }\end{array}$ & nomina \\
\hline
\end{tabular}

Pada tabel di atas, dapat dilihat bahwa alat untuk memanen dan pascapanen pada masyarakat suku Paser menggunakan banyak alat yang sederhana, yaitu ditemukan sembilan bentuk kosakata alat. Kesembilan kosakata tersebut berkelas kata nomina dan merupakan bentuk dasar semua. Berikut ini akan dijelaskan secara singkat konsep makna dari kesembilan kosakata alat untuk memanen dan pascapanen tersebut. Kata renggap memiliki konsep makna alat pemotong padi terbuat dari kayu dan bambu yang saling menyilang dengan pisau kecil atau silet yang ditancapkan pada bagian mata kayu, penggunaannya dijepit di jari tangan, biasanya digunakan oleh perempuan. Kata selombang mengacu pada makna alat pemotong padi yang terbuat dari potongan kaleng bekas yg digulung, panjangnya 
menyesuaikan jari jempol, cara memakainya dengan memasukkan selombang tersebut di tangan bagian jari jempolnya, biasanya digunakan oleh kaum laki-laki. Kata solong, yaitu sejenis tas besar yang terbuat dari rotan yang dianyam rapat, diberi dua tali (kanan dan kiri), cara memakainya dengan digendong di punggung, dapat digunakan oleh kaum laki-laki ataupun perempuan. Kata kirai bermakna sejenis keranjang atau lanjung yang besar, berfungsi untuk tempat penumpukan atau pengumpulan padi dari solong yang sudah terisi penuh petikan padi, biasanya diletakkan di tanah, di pinggir atau tengah ladang atau di dekat orang-orang yang memanen.

Sementara itu, kata selipir mengacu pada makna tempat penumpukan padi yang berada di rumah atau seperti lumbung padi, biasanya terbuat dari kulit kayu atau daun nipah yang dibentuk segi empat, kemudian dibentuk seperti tong besar sehingga dapat menampung padi yang banyak. Frasa tekalak bua pare mengacu pada konsep makna bambu yang dianyam seperti bubu yang diletakkan di tengahtengah selipir sampai dasar selipir agar padi tidak lembab dan tidak tumbuh. Kata jakung atau jayung memiliki konsep makna alas untuk menginjak padi dan membantu untuk merontokkan atau membersihkan padi dari tangkainya, terbuat dari bambu yang dianyam seperti tikar, tetapi ada rongga-rongganya agar padi bisa keluar atau turun ke bawah. Alat ini diletakkan di pondok panggung khusus untuk meletakkan jakung tersebut. Kata lewong atau usar bermakna sejenis tampi untuk membersihkan padi dari kotorannya. Biasanya yang menampi padi dengan menggunakan lewong atau usar ini adalah kaum perempuan. Kata pendakak mengacu pada makna sejenis tikar yang terbuat dari daun nipah atau dari rotan yang dianyam, ukurannya 1 meter sampai dengan 2 meter. Fungsinya untuk menjemur padi yang sudah dibersihkan

\section{PENUTUP}

Berdasarkan hasil penelitian dan pembahasan, dapat disimpulkan beberapa hal sebagai berikut. Deskripsi data lapangan yang diperoleh peneliti terhadap peristilahan berladang padi pada masyarakat suku Paser berjumlah 35kosakata yang terdiri ataslima klasifikasi, yaitu(a) proses pratanam berjumlah 9 kosakata, (b) alat membuka ladang berjumlah 4 kosakata, (c) proses menanam dan merawat padi berjumlah 4 kosakata, (d) proses memanen dan pascapanen berjumlah 9 kosakata, dan (e) alat untuk memanen dan pascapanen berjumlah 9 kosakata. Analisis konsep makna secara semantik juga dikaitkan dengan makna kultural masyarakat setempat karena dapat memperjelas makna kosakata berladang tersebut.

Berdasarkan pembahasan dan simpulan, ada beberapa saran yang diajukan, antara lain, sebagai berikut. Kajian terhadap kosakata berladang suku Paser di Kecamatan Long Ikis dapat mendokumentasikan sesuatu yang unik dan saat ini sudah jarang ditemukan. Oleh karena itu, perlu dilakukan dengan objek bahasabahasa daerah lainnya, khususnya bahasa-bahasa yang terdapat di Kalimantan Timur. Hasil penelitian ini diharapkan dapat digunakan untuk menambah data penyusunan kamus kosakata tematik perladangan. Selain itu, kosakata daerah mengenai perladangan ini dapat diusulkan untuk pengayaan kosakata bahasa Indonesia melalui Kamus Besar Bahasa Indonesia dalam jaringan. 


\section{DAFTAR PUSTAKA}

Aminuddin. (2003). Semantik: Pengantar Studi tentang Makna. Bandung: Sinar Baru Algensindo.

Badan Pengembangan dan Pembinaan Bahasa. (2017). Bahasa dan Peta Bahasa di Indonesia. Jakarta: Kementerian Pendidikan dan Kebudayaan.

Chaer, Abdul. (2013). Pengantar Semantik Bahasa Indonesia. Jakarta: Rineka Cipta.

Kridalaksana, Harimurti. (2008). Kamus Linguistik. Jakarta: Gramedia Pustaka Utama.

Miles, Matthew B. dan A. Michael Huberman.(2007). Analisis Data Kualitatif. (Terj. Tjetjep Rohendi Rohidi). Jakarta: UI-Press.

Muhidin, Rahmat. (2015). "Kosakata Budaya yang Berhubungan dengan Adat Perkawinan Melayu Bangka di Kota Pangkalpinang”. Dalam Widyaparwa Volume 43, Nomor 1, Juni 2015, Halaman.79—88. Yogyakarta: Balai Bahasa Provinsi daerah Istimewa Yogyakarta.

Pateda, Mansoer. (2010). Semantik Leksikal. Jakarta: PT Rineka Cipta.

Rahman, Abd., dkk. (2014). Pemetaan dan Hubungan Kekerabatan Bahasa Daerah di Kabupaten Paser.Samarinda: Kantor Bahasa Provinsi Kalimantan Timur.

Rusbiyantoro, Wenni, dkk. (2014). Kamus Bahasa Paser-Bahasa Indonesia. Samarinda: Kantor Bahasa Provinsi Kalimantan Timur.

Septiandi, dkk. (2015). "Kosakata Berladang Padi Suku Dayak Kubitn Kecamatan Pinoh selatan: Kajian Semantik Leksikal”. Dalam https:/www.ejurnal.com/2015.

Suwandi, Sarwiji. (2008). Semantik: Pengantar Kajian Makna. Yogyakarta: Media Perkasa.

Widoyoko, Eko Putro. (2013). Teknik Penyusunan Instrumen Penelitian. Yogyakarta: Pustaka Pelajar. 